\title{
Emerging therapies for Clostridium difficile infection - focus on fidaxomicin
}

\author{
This article was published in the following Dove Press journal: \\ Infection and Drug Resistance \\ 27 June 2013 \\ Number of times this article has been viewed
}

\author{
Fredy Chaparro-Rojas \\ Kathleen M Mullane \\ Department of Medicine, Section \\ of Infectious Diseases, University \\ of Chicago, Chicago, IL, USA
}

Correspondence: Kathleen M Mullane University of Chicago, Department of Medicine/Section of Infectious Diseases, 584I South Maryland Avenue, MC 5065, Chicago, IL, USA 60637

Tel + I 7737023756

Fax + 17737023746

Email kmullane@medicine.bsd.uchicago. edu

\begin{abstract}
The epidemiology of Clostridium difficile infections (CDI) has evolved during the last decades, with an increase in the reported incidence, severity of cases, and rate of mortality and relapses. These increases have primarily affected some special populations including the elderly, patients requiring concomitant antibiotic therapy, patients with renal failure, and patients with cancer. Until recently, the treatment of CDI was limited to either metronidazole or vancomycin. New therapeutic options have emerged to address the shortcomings of current antibiotic therapy. Fidaxomicin stands out as the first-in-class oral macrocyclic antibiotic with targeted activity against $C$. difficile and minimal collateral damage on the normal colonic flora. Fidaxomicin has demonstrated performance not inferior to what is considered the "gold standard" available therapy for CDI, vancomycin, in two separate Phase III clinical trials, but with significant advantages, including fewer recurrences and higher rates of sustained clinical cures. Fidaxomicin constitutes an important development in targeted antibiotic therapy for $\mathrm{CDI}$ and must be considered as a first-line agent for patients with risk factors known to portend relapse and severe infection.
\end{abstract}

Keywords: fidaxomicin, Clostridium difficile-associated diarrhea, CDAD, Clostridium difficile infection (CDI), vancomycin, metronidazole

\section{Introduction}

Clostridium difficile, a gram-positive anaerobic spore-forming bacillus, has been implicated in $20 \%$ to $30 \%$ of cases with antibiotic-associated diarrhea; in $50 \%$ to $70 \%$ of those with antibiotic-associated colitis; and in more than $90 \%$ of those with antibiotic-associated pseudomembranous colitis. ${ }^{1}$ Collectively, these conditions are commonly known as $C$. difficile infections (CDI). ${ }^{2-4}$ In 2009, over 336,000 cases of CDI were reported in the United States. ${ }^{5}$ In nature, $C$. difficile exists as a spore and it is postulated that in vivo sporulation to the vegetative or toxin-producing form of this organism is suppressed by the presence of normal intestinal microflora. CDI results from a combination of disruption of the normal intestinal microflora and sporulation, and the overgrowth of native or newly acquired $C$. difficile spores with an associated production of clostridial glycosylating toxins. ${ }^{6,7}$ Because antibiotics alter the intestinal microflora, antibiotic administration is the most common predisposing factor for acquiring CDI. ${ }^{1}$ Other proposed mechanisms by which antibiotics might further influence the risk of CDI include alteration of colonic adhesion of $C$. difficile and induction of toxin production. ${ }^{8,9}$

The epidemiology and clinical presentation of CDI has changed during the last decades with an increased incidence of cases; more severe presentations; more frequently 
reported disease in community settings; and higher rates of refractory, relapsing disease. ${ }^{10}$ Rising incidence of CDI and increasing rates of complicated disease with limited therapeutic options have prompted research for new agents to treat this condition. Because there are no randomized controlled trials evaluating the management of patients with severe complicated or recurrent disease, these entities remain a challenge. Recent efforts have focused on issues such as reducing the risk of treatment failures and recurrences; reducing treatmentrelated systemic adverse effects; preserving the intestinal microbiota; and optimizing humoral immunity. The aims of this article are to review treatment options for CDI and to describe recent therapeutic advancements in management with an emphasis on the newest available agent approved for treatment of CDI, fidaxomicin.

Patients with classical manifestations of CDI such as diarrhea, abdominal pain, nausea, vomiting, and a positive diagnostic test for $C$. difficile should receive treatment. ${ }^{1}$ Familiarity with the basic CDI definitions can help treating physicians select the appropriate pharmacologic intervention in given cases based upon severity of the disease (Table 1). These definitions are based on expert opinion, as published in the most current guidelines for the management of CDI. ${ }^{1}$ The initial step in treating CDI, as recommended in the guidelines, is the withdrawal of any offending antibiotic known to be associated with the development of the disease. ${ }^{1,11}$ Unfortunately, in many clinical situations, patients require concomitant systemic antimicrobials for concurrent infection(s), resulting in higher rates of treatment failures and recurrent disease. ${ }^{12}$

\section{Antibiotic treatment options for CDI Vancomycin}

Until the US Food and Drug Administration (FDA) approved fidaxomicin in May 2011, vancomycin was the only FDA approved agent for the treatment of CDI. The current published CDI guidelines, developed prior to the release of fidaxomicin, advocate for treatment with oral metronidazole in cases of mild to moderate disease, oral vancomycin for serious CDI, and combination therapy with enteral vancomycin and intravenous metronidazole in cases of ileus or toxic megacolon (Table 1). ${ }^{1,13}$ New and alternative pharmacological regimens used for the management of CDI are outlined in Table 2.

\section{Metronidazole}

Widespread use of metronidazole over vancomycin was advocated in the 1995 Healthcare Infection Control Practices Advisory Committee guidelines in an effort to reduce the spread of vancomycin-resistant Enterococci (VRE). ${ }^{14}$ However, acquisition of VRE may arise from exposure to either metronidazole or vancomycin. ${ }^{15}$ Recent reports show declining efficacy of metronidazole. ${ }^{16-18}$ Rates of treatment failure have increased from $\sim 3 \%$ before the year 2000 to $>18 \%$ after $2000 .{ }^{18}$ Although treatment failures may be related to reduced susceptibility of $C$. difficile strains, treatment failures could as well be related to inadequate fecal concentrations of metronidazole. ${ }^{19-21}$

Metronidazole remains a widely used agent for CDI treatment given its inexpensive cost and availability. Two randomized trials, however, have shown vancomycin to be superior to metronidazole for severe, but not for mild to moderate, CDI disease. ${ }^{16,17}$ Limitations of metronidazole include side effects of nausea, metallic taste, disulfiram reactions with alcohol use, dose-dependent irreversible peripheral neuropathy, and inferior efficacy in severe CDI.

Until 2011, oral vancomycin was the only FDA approved treatment for CDI, making it the only comparator in

Table I Definitions and recommendations for the treatment of Clostridium difficile infection

\begin{tabular}{|c|c|c|}
\hline Clinical definition & Clinical and laboratory data & Recommended therapy \\
\hline $\begin{array}{l}\text { Initial episode, } \\
\text { mild or moderate }\end{array}$ & $\begin{array}{l}\text { Leukocytosis with } \mathrm{WBC} \leq 15,000 \text { cells } / \mu \mathrm{L} \\
\text { serum creatinine level } \leq 1.5 \text { times the baseline level. }\end{array}$ & $\begin{array}{l}\text { Metronidazole } 500 \mathrm{mg} \text { PO every } 8 \text { hours for } \\
10-14 \text { days. }\end{array}$ \\
\hline $\begin{array}{l}\text { Initial episode, } \\
\text { severe }\end{array}$ & $\begin{array}{l}\text { Leukocytosis with } W B C \geq 15,000 \text { cells } / \mu \mathrm{L} \\
\text { serum creatinine level } \geq 1.5 \text { times the baseline level. }\end{array}$ & $\begin{array}{l}\text { Vancomycin } 125 \mathrm{mg} \text { PO every } 6 \text { hours for } \\
\text { 10-14 days. }\end{array}$ \\
\hline $\begin{array}{l}\text { Initial episode, } \\
\text { severe complicated }\end{array}$ & Hypotension or shock, ileus, megacolon. & $\begin{array}{l}\text { Vancomycin } 500 \mathrm{mg} \text { PO/NG tube every } 6 \text { hours, } \\
\text { plus metronidazole } 500 \mathrm{mg} \text { IV every } 8 \text { hours. If } \\
\text { complete ileus, consider vancomycin rectal enemas. }\end{array}$ \\
\hline First recurrence & - & Same as for initial episode. \\
\hline Second recurrence & - & Vancomycin tapered and/or pulse regimen. \\
\hline
\end{tabular}

Adapted with permission from Cohen SH, Gerding DN, Johnson S, et al; for Society for Healthcare Epidemiology of America, Infectious Diseases Society of America. Clinical practice guidelines for Clostridium difficile infections in adults: 2010 update by the society for healthcare epidemiology of America (SHEA) and the infectious diseases society of America (IDSA). Infect Control Hosp Epidemiol. 2010;3I(5):43I-455.'

Abbreviations: WBC, white blood cell; PO, orally; NG, nasogastric; IV, intravenously. 


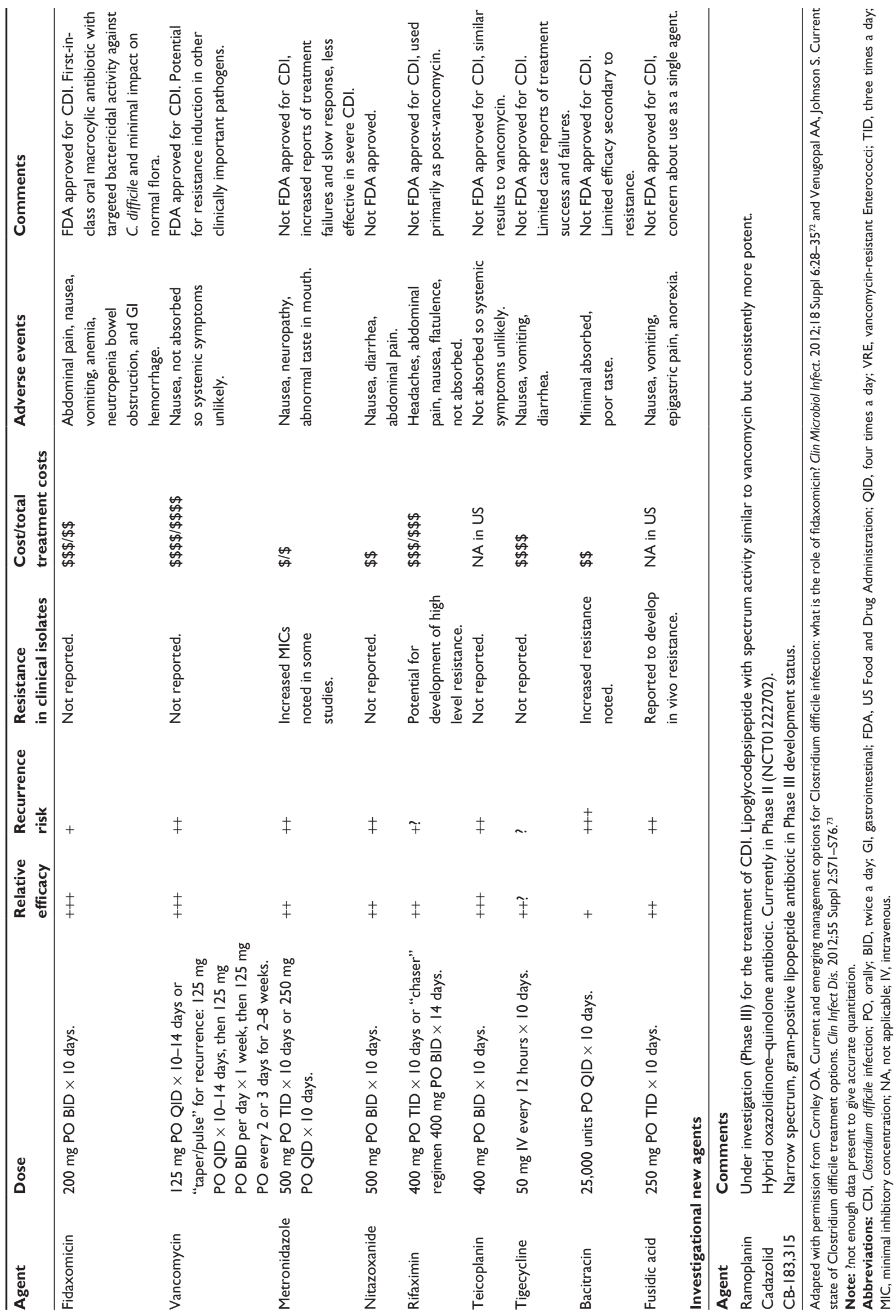


studies evaluating new agents for this indication. ${ }^{17,22,23}$ Advantages over metronidazole include high intraluminal concentrations with low levels of systemic absorption after oral administration and higher efficacy for treatment of primary episodes of CDI, especially in severe cases. Limits to its widespread use include high levels of relapse (25\%-35\% in four recent clinical trials), acquisition cost, and concerns for bacterial colonization and overgrowth of Staphylococcus and Enterococcus, including vancomycin-resistant strains. ${ }^{1,16,17,22-24}$ Multiple treatment strategies for management of recurrent CDI including use of higher doses and/or extended duration of vancomycin therapy have not shown improved clinical outcomes. Prolonged vancomycin given either as a tapered regimen or in pulsed dosing, postulated to allow recovery of intestinal microbiota while inhibiting germination of residual spores, have shown higher rates of cure and fewer recurrences compared to standard 10-14 day regimens. ${ }^{25,26}$

\section{Fidaxomicin, a new therapeutic alternative for CDI}

Fidaxomicin, a first-in-class 18-membered macrocyclic antibiotic previously known as OPT-80, PAR-101, and difimicin was approved in May 2011 by the FDA for the treatment of adults with CDI. ${ }^{27-29}$

\section{Mechanism of action}

Fidaxomicin is a bactericidal antibiotic that has a lower in vitro minimum inhibitory concentration (MIC) against $C$. difficile strains, including NAP1/B1/027, than does metronidazole or vancomycin. ${ }^{30}$ It has very limited activity against other bowel flora and modest activity against Staphylococcus spp. and Enterococcus, including vancomycin-resistant Enterococcus. ${ }^{31}$ It inhibits bacterial protein transcription by interfering with ribonucleic acid (RNA) polymerase, producing a rapid suppression of RNA synthesis, followed by an inhibition of protein synthesis and, ultimately, deoxyribonucleic acid synthesis. ${ }^{32-34}$ It acts at a different site and step of RNA synthesis than rifamycins, and thus far no overlapping antibiotic resistance has been described. ${ }^{34-36}$ Fidaxomicin is more potent at suppressing clostridial RNA polymerase than against other bacterial species.

\section{Efficacy studies and comparative analysis}

Two large, concurrently run, double-blind randomized noninferiority trials (OPT 101.1.C.003 and OPT 101.1.C. 004), compared fidaxomicin to vancomycin in the treatment of CDI. ${ }^{22,23}$ Patients with a new onset or first recurrence of CDI within 3 months prior to randomization were assigned to receive either fidaxomicin (200 mg twice daily) or vancomycin (125 mg four times daily) orally for 10 days. The primary endpoint of a noninferior clinical cure (resolution of CDI symptoms and no need for further therapy at the end of therapy) between the two treatment arms was met in both the modified intention-to-treat analysis and the per-protocol analysis (Figure 1). The analysis of secondary endpoints of CDI recurrence and global cure (clinical cure and no recurrence of disease at 28 days after completion of study drug therapy) showed that significantly fewer patients in the fidaxomicin group than in the vancomycin group had recurrence of CDI (Figure 2), and consequently, those treated with fidaxomicin

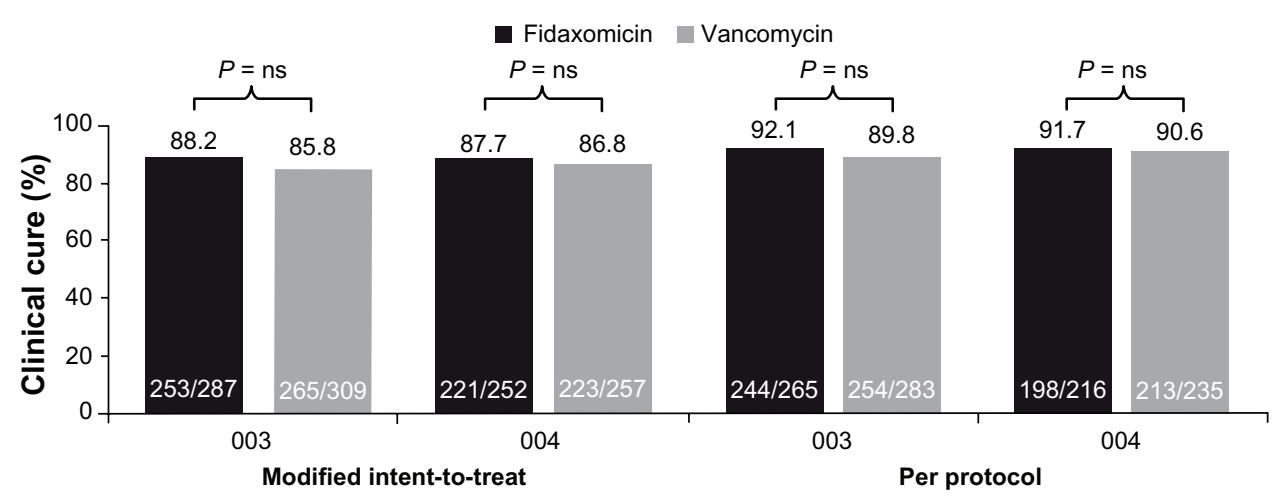

Figure I Rates of clinical cure at end of treatment (primary efficacy endpoint) in the fidaxomicin Phase III trials (studies 003 and 004 ). 22,23

Notes: Modified intent-to-treat: patients underwent randomization and received $\geq \mathrm{I}$ dose of study medication. Per protocol: patients in the modified intent-to-treat population who received $\geq 3$ days of study medication (in cases of failure) or $\geq 8$ days (in cases of clinical cure) with documented adherence to study protocol and who underwent end-of-treatment evaluation.

Reproduced with permission from Cornley OA. Current and emerging management options for Clostridium difficile infection: what is the role of fidaxomicin? Clin Microbiol Infect. 2012;18 Suppl 6:28-3572 and Louie TJ, Miller MA, Mullane KM, et al; for OPT-80-003 Clinical Study Group. Fidaxomicin versus vancomycin for Clostridium difficile infection. N Engl J Med. 20 I I;364(5):422-43।.22

Abbreviation: ns, not significant. 


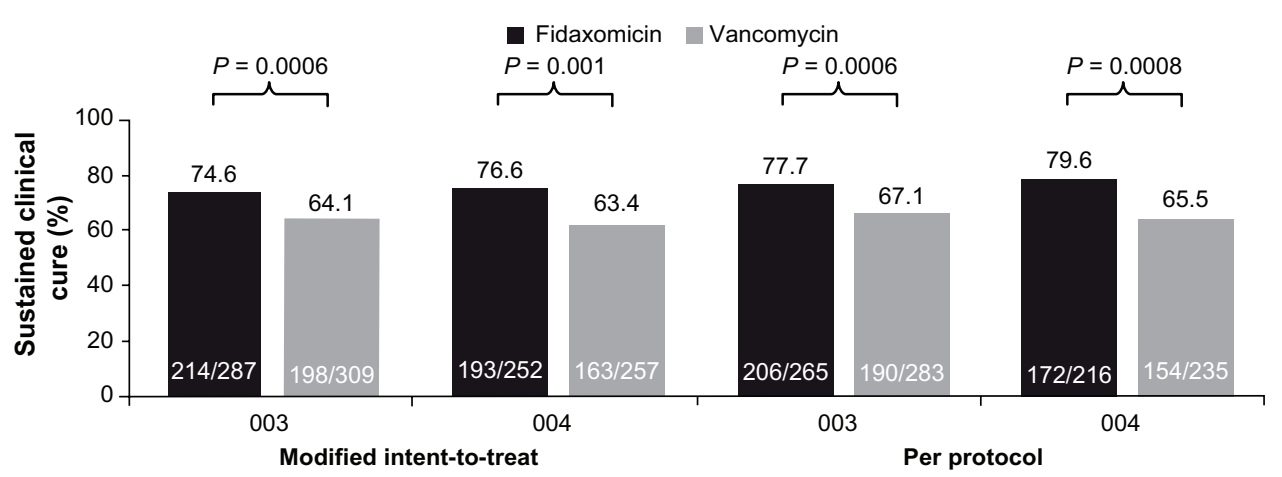

Figure 2 Rates of sustained clinical cure (clinical cure without recurrence of diarrhoea during the 30-day follow-up period) in the fidaxomicin Phase III trials (studies 003 and 004). ${ }^{22,23}$

Notes: Modified intent-to-treat: patients underwent randomization and received $\geq \mathbf{I}$ dose of study medication. Per protocol: patients in the modified intent-to-treat population who received $\geq 3$ days of study medication (in cases of failure) or $\geq 8$ days (in cases of clinical cure) with documented adherence to study protocol and who underwent end-of-treatment evaluation.

Reproduced with permission from Cornley OA. Current and emerging management options for Clostridium difficile infection: what is the role of fidaxomicin? Clin Microbiol Infect. 2012; 18 Suppl 6:28-3572 and Louie TJ, Miller MA, Mullane KM, et al; for OPT-80-003 Clinical Study Group. Fidaxomicin versus vancomycin for Clostridium difficile infection. N Engl J Med. 20I I;364(5):422-431.22

had a statistically significant improved rate of global cure. Although the numbers of subjects who were infected with NAP1/BI/027 strains in these trials were small, the rates of cure and global cure in the per-protocol analysis were not significantly different in those treated with fidaxomicin than in those treated with vancomycin.

A post hoc exploratory intent-to-treat time-to-event meta-analysis of the combined data from these two trials was performed, to allow increased power with 1164 total subjects, using a fixed effects meta-analysis and Cox regression models. ${ }^{37}$ There was no evidence found of heterogeneity in the primary and secondary outcomes in either the modified intention-to-treat or per-protocol populations $(P>0.3)$. Overall, the results of this analysis again demonstrated noninferiority of fidaxomicin when compared to vancomycin for clinical cure and superiority of fidaxomicin over vancomycin in reduction of recurrence and global cure $(P<0.0001)$. When compared to vancomycin, treatment with fidaxomicin was associated with an overall $40 \%$ reduction in persistent diarrhea, recurrence, or death through the 40 -day study period ( $P<0.001)$. There was no evidence to show that the significant differences in relapse and global cure in the fidaxomicin- compared to the vancomycintreated subjects was altered according to disease severity, prior history of CDI, previous antibiotic therapy for CDI, inpatient/outpatient status, age, or baseline albumin or creatinine levels. Patients treated with fidaxomicin for CDI due to non-NAP1/BI/027 strains and with hemoglobin levels higher than $10 \mathrm{~g} / \mathrm{dL}$ experienced a greater benefit than those infected by NAP/1/BI/027 strains or with hemoglobin levels lower than $10 \mathrm{~g} / \mathrm{dL}$. In the case of severe anemia, there is no obvious explanation for this finding; however, this interaction did not persist in a fully adjusted multivariate model suggesting a potential confounder. On the other hand, both subgroup analyses and multivariate analysis confirmed the smaller benefit appreciated in the few patients enrolled who were infected with NAP1/BI/027 strains treated with fidaxomicin. Of note, the data showed a nonstatistically significant $22 \%$ reduction in persistent or recurrent diarrhea or death in those with NAP-1strain infections. Given that only 292 of the 814 strains assayed were NAP1/ $\mathrm{BI} / 027$, even in the combined dataset the number of cases was underpowered to definitively conclude whether or not fidaxomicin has a beneficial effect for treating CDI due to NAP1/BI/027 strains. ${ }^{37}$

Certain groups of patients with CDI are at a significantly higher risk of recurrences including older patients, patients requiring concomitant antibiotic therapy, patients with severe renal impairment, cancer patients, and those with severe CDI (Figure 3). Post hoc subgroup analysis of combined data from studies OPT 101.1.C.003 and OPT 101.1.C.004 explored these high-risk populations. Overall, use of fidaxomicin in patients with conditions associated with a high risk for recurrence had significantly improved outcomes. ${ }^{12,37-41}$

In the subjects that required concomitant antibiotic therapy for concurrent infections randomized to fidaxomicin, the cure rate was $90.0 \%$ compared with $79.4 \%(P=0.04)$ in those treated with vancomycin. ${ }^{12}$ Fidaxomicin therapy was associated with $12.3 \%$ less recurrences compared to vancomycin therapy $(P=0.048)$. In subjects with renal impairment (RI), CDI cures declined and recurrences increased with progressively declining renal function. ${ }^{37,38}$ 


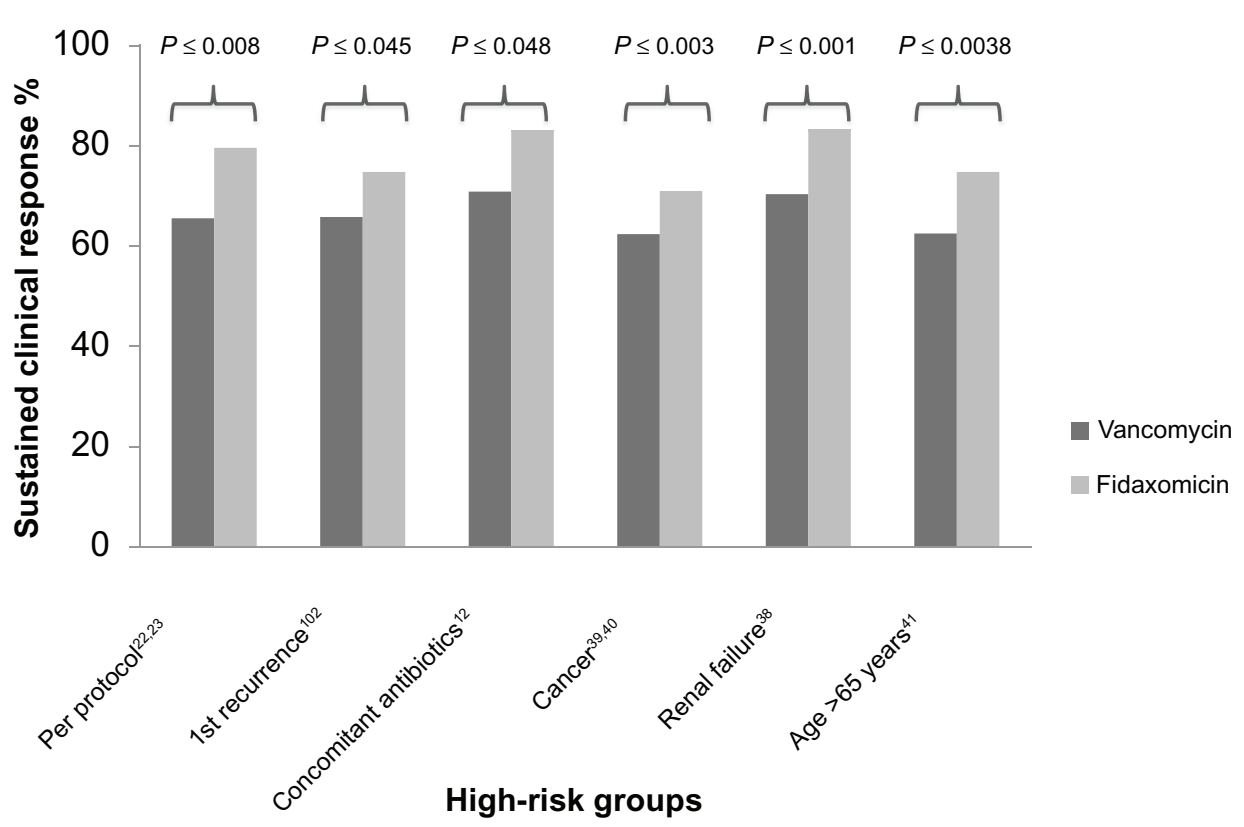

Figure 3 Rates of high-risk patients achieving sustained clinical response (vancomycin versus fidaxomicin).

Cure rates were similar for normal (91\%) and mild RI (92\%), but fell to $80 \%$ for moderate and $75 \%$ for severe RI $(P<0.001)$. Recurrence rates were $16 \%, 20 \%, 27 \%$, and $24 \%$ for normal, mild, moderate, and severe RI $(P=0.009)$. Fidaxomicin was associated with significantly lower odds of recurrence (odds ratio $[\mathrm{OR}]=0.46$, confidence interval $[\mathrm{CI}]$ $0.32-0.66$ ) and superior sustained response ( $\mathrm{OR}=1.85$, CI $1.39-2.47)$ than vancomycin. In patients with severe renal dysfunction, recurrence occurred in $15 \%$ of fidaxomicintreated subjects compared to $35 \%$ of those randomized to vancomycin. Odds of recurrence were 54\% lower and odds of sustained response were $85 \%$ greater with fidaxomicin relative to vancomycin. In patients with a diagnosis of cancer, CDI cure was more likely in those randomized to fidaxomicin than in subjects on vancomycin $(P=0.041)$, recurrence was less likely $(P=0.025)$, and the sustained response rate was significantly higher $(P=0.03) .{ }^{39,40} \mathrm{~A}$ post hoc analysis, using regression modeling of the two pivotal double-blind randomized multicenter studies, showed that in comparison to vancomycin, those patients who were treated with fidaxomicin had a $60 \%$ lower risk of recurrence after adjusting for age, concomitant antibiotics, and $C$. difficile strain. $^{41}$

\section{Advantages}

Fidaxomicin has potential advantages over other drugs used to treat CDI and a number of properties that appear to be ideally suited to the treatment of CDI ${ }^{42}$ Fidaxomicin is bactericidal, with lower MICs against $C$. difficile when compared to vancomycin and metronidazole, and it has a prolonged postantibiotic effect of approximately 10 hours (range 9.5-12.5 hours) allowing for twice daily dosing. ${ }^{43}$ After oral dosing, fidaxomicin achieves fecal concentrations well above the $\mathrm{MIC}_{90}$ of $0.25 \mathrm{mcg} / \mathrm{mL}$ for $C$. difficile with fecal concentrations within 24 hours of the last dose of 639-2710 mcg/g for fidaxomicin and $213-1210 \mathrm{mcg} / \mathrm{g}$ for OP-1118, the major metabolite of fidaxomicin. Fidaxomicin has minimal systemic absorption with plasma concentrations within the Tmax window (1-5 hours) of $0.3-197 \mathrm{ng} /$ $\mathrm{mL}$ for fidaxomicin and $0.29-871 \mathrm{ng} / \mathrm{mL}$ for OP-1118, even in patients with severe CDI. ${ }^{43-48}$ Fidaxomicin has a very narrow spectrum of antimicrobial activity when compared to vancomycin and metronidazole; therefore, it has less impact on the normal intestinal microbiota, predominantly on the members of clostridial clusters XIVa and IV, the Bacteroides/Prevotella group, and it has an indifferent effect on bifidobacteria. ${ }^{49-51}$ Clinical and bacteriological cure in patients with CDI is therefore achieved with minimal effects on the composition of the microbiome, thus allowing for a more rapid restoration of the commensal microflora, thereby reducing the risk of $C$. difficile colonization, reinfection, and proliferation. ${ }^{49,51}$ Fidaxomicin has moderate activity against other gram-positive organisms, including Staphylococcus $s p$. and Enterococci..$^{31,34}$ In a recent study, treatment for CDI with fidaxomicin was less likely to promote acquisition of VRE and candida species when compared to vancomycin, a potential benefit in the relationship with infection control implications. ${ }^{50}$ Fidaxomicin blocks gene transcription, 
halting bacterial sporulation and suppressing toxin production. ${ }^{51-53}$ Reappearance of toxin in fecal filtrates was observed in $28 \%$ of vancomycin-treated patients samples (29 of 94 ), compared with $14 \%$ of fidaxomicin-treated patient samples (13 of 91; $P=0.03$ ). ${ }^{51}$ In a recent study, the effects of fidaxomicin, its major metabolite (OP-1118), vancomycin, and metronidazole on the expression of toxin genes and toxin proteins in four strains of $C$. difficile, including two hypervirulent NAP1/BI/027 isolates, were compared. ${ }^{52}$ Subinhibitory levels of fidaxomicin and OP-1118, but not vancomycin or metronidazole, suppressed both sporulation and toxin production $(>60 \%)$ in $C$. difficile through at least 1 week of culture. ${ }^{52,53}$ Suppression of toxin production may contribute to the improved sustained clinical response observed with fidaxomicin when compared to vancomycin. ${ }^{51,52}$ Inhibition of sporulation may well impact the rate of recurrences seen in patients treated with fidaxomicin in comparison to vancomycin and reduction of the shedding of spores has the potential benefit of decreasing transmission of $C$. difficile in hospital settings; however, further studies are needed to determine this impact of fidaxomicin on $C$. difficile transmission. ${ }^{53}$

Based on online reviews, the patient satisfaction ratings are very favorable with rapid resolution of symptoms and frequency of diarrhea even after failed attempts of therapy with vancomycin and metronidazole. ${ }^{54-56}$

\section{Safety and tolerability}

In nonclinical studies, high doses of fidaxomicin were administered to dogs (approximately $1 \mathrm{~g} / \mathrm{kg}$ /day) with no target organ toxicities reported. ${ }^{48}$ In the Phase III clinical trials, the safety profile of fidaxomicin was comparable with oral vancomycin with no differences in the rates of serious adverse events or death. ${ }^{22,23}$

Anemia and leukopenia have been reported in patients receiving fidaxomicin and vancomycin at almost identical rates, although no specific bone marrow toxicity was observed with fidaxomicin in the nonclinical trials. In patients who developed leukopenia, the incidence of infection resulting in death was similar between fidaxomicin (2\%) and vancomycin $(1.9 \%)$.

Fidaxomicin is FDA category B for pregnancy as animal reproduction studies have failed to demonstrate any risk to the fetus; however, there are no adequate and well controlled studies in pregnant women. ${ }^{48}$ The available evidence is inadequate for determining infant risk when used during breastfeeding, and caution is advised when administering fidaxomicin to a nursing mother.

\section{Other antibiotics}

\section{Nitazoxanide}

In small trials, nitazoxanide efficacy appears to be comparable to metronidazole and vancomycin for the treatment of CDI. ${ }^{57,58}$ Given limited studies and high cost, nitazoxanide use for the management of CDI is uncommon.

\section{Rifaximin}

Rifaximin is a semisynthetic, nonsystemic antibiotic with excellent in vitro activity against $C$. difficile and limited impact on the intestinal microbiome. Uncontrolled small studies have evaluated rifaximin for the management of CDI unresponsive to multiple courses of metronidazole and vancomycin. ${ }^{59-62}$ Use of rifaximin in treating CDI is limited by sparse supportive evidence, acquisition cost, and due to reports of the development of $C$. difficile resistance associated with its use for CDI treatment.

\section{Teicoplanin}

It has in vitro activity that is comparable to that of vancomycin against $C$. difficile. Teicoplanin has been found to be superior to vancomycin for curing CDI; however, these clinical trial results should be interpreted with caution given that these data were derived from studies with small numbers of patients and a high risk of bias. ${ }^{63,64}$ Teicoplanin is not available for use in the United States.

\section{Bacitracin}

In a randomized, double blind, crossover trial, oral bacitracin demonstrated comparable effectiveness to vancomycin for the treatment of CDI. ${ }^{65}$ Bacitracin, was found to be less effective than vancomycin in eradicating $C$. difficile and its toxin from patients' stools; however, no relationship between the development of recurrences and the presence of $C$. difficile and its toxins at the end of therapy could be discerned. Given in vitro evidence of resistance, bacitracin is considered to have a limited role in the therapy of CDI. ${ }^{64}$

\section{Tigecycline}

Limited case reports have suggested that tigecycline alone or in combination with more traditional therapeutic options like vancomycin or metronidazole, could be used in the treatment of severe CDI when prior therapy has failed. ${ }^{66}$ The precise role of tigecycline in the treatment of CDI remains unclear and further studies are needed.

\section{Fusidic acid}

Fusidic acid was compared to metronidazole in the first episode of CDI. In the fusidic acid group, $83 \%$ were clinically 
cured in comparison to $93 \%$ in the metronidazole group $(P=0.116)$ at the first follow-up visit, and the rates were $27 \%$ and $29 \%$, respectively. ${ }^{67,68}$ The development of resistance in C. difficile is frequent in patients treated with fusidic acid with no apparent negative impact on therapeutic efficacy noted. ${ }^{67,68}$

\section{Investigational new antimicrobial and nonantimicrobial agents}

Numerous antibiotic and non-antibiotic alternatives for the treatment of CDI have been recently described or are currently under study evaluation.

\section{Ramoplanin}

Ramoplanin is a lipoglycodepsipeptide antibacterial with similar, but considerably more potent activity than vancomycin against $C$. difficile and VRE, with little impact on anaerobic organisms and no cross resistance to vancomycin reported to date..$^{64,69,70}$ In a Phase II study, ramoplanin was compared to vancomycin for CDI treatment in 86 subjects who were randomly assigned to receive 10 days of oral therapy with either ramoplanin $200 \mathrm{mg}$ twice daily $(\mathrm{n}=28)$, ramoplanin $400 \mathrm{mg}$ twice daily $(\mathrm{n}=29)$, or vancomycin $125 \mathrm{mg}$ orally four times daily $(\mathrm{n}=29) .{ }^{71}$ Clinical cure, defined as either complete or partial response, was achieved in $83 \%$ of the ramoplanin $200 \mathrm{mg}$ arm, $85 \%$ in the $400 \mathrm{mg}$ group, and $86 \%$ in the vancomycin group. Ramoplanin appeared to be equally effective compared to vancomycin, but larger trials are necessary to further elucidate its role in the treatment of CDI. A Phase III noninferiority protocol with vancomycin as the comparator has been approved by the FDA.

\section{CB- 183,315}

CB-183,315 is an orally available lipopeptide antibiotic, currently in Phase III clinical development, that is structurally related to daptomycin with in vitro efficacy against VRE and C. difficile, including strains resistant to fluoroquinolones and metronidazole, and with elevated MICs to vancomycin. ${ }^{74,75}$ A Phase II study compared two doses (125 mg versus $250 \mathrm{mg}$ twice daily) of CB-183,315 to vancomycin (125 mg four times daily) in 209 subjects with CDI. ${ }^{24}$ The higher dose CB-183,315 demonstrated a clinical cure rate comparable to oral vancomycin. However, while recurrence or relapse was $35.6 \%$ in the oral vancomycin arm and $27.9 \%$ in the low dose CB-183,315, in the high dose CB-183,315 group it was only $17.2 \%(P=0.035)$. The NAP1/BI/027 strain of $C$. difficile was isolated in $32 \%$ of subjects in this trial. The clinical response rate in these subjects was comparable across the CB-183,315 and oral vancomycin groups. A modest, but not statistically significant, reduction in relapse rates in those treated with CB-183,315 was noted.

\section{Non-antibiotic therapeutic alternatives}

The immune response to $C$. difficile colonization is the major determinant of the magnitude and duration of clinical manifestations. Intravenous immunoglobulin (IVIg), monoclonal antibodies, immunization, and donor fecal transplantation have been used in recent years with encouraging results or are currently under study (Table 3 ).

Table 3 Non-antibiotic alternatives and investigational new agents for the management of CDI

\begin{tabular}{|c|c|}
\hline & Comments \\
\hline \multicolumn{2}{|l|}{ Agent } \\
\hline IVlg & $\begin{array}{l}\text { Multisystemic side effect profile. Most commonly renal failure. Efficacy for use in adults is inconclusive; } \\
\text { in pediatrics, evidence favors efficacy. }\end{array}$ \\
\hline Fecal transplantation & $\begin{array}{l}\text { Infusion of feces from a healthy donor. Most evidence comes from single center case series and case reports. } \\
\text { A recent multicenter, long-term follow-up study has shown positive results. }\end{array}$ \\
\hline Probiotics & $\begin{array}{l}\text { Multiple studies favor the use of probiotics for the prevention of CDI and antibiotic-associated diarrhea; }{ }^{90-92} \\
\text { however, appropriately powered studies are needed to confirm these findings. Guidelines do not recommend } \\
\text { the routine use of probiotics given the lack of definitive evidence of effectiveness and potential risk of blood } \\
\text { stream infection. }\end{array}$ \\
\hline \multicolumn{2}{|c|}{ Investigational new agents } \\
\hline CDAl and $\mathrm{CDBI}$ & $\begin{array}{l}\text { Human monoclonal antibodies against C. difficile toxins A and B. Phase III trial for prevention of CDI, } \\
\text { recurrence (MODIFY I [NCT0I24I552] and MODIFY II [NCTOI5I3239]). }{ }^{83,84}\end{array}$ \\
\hline ACAM-CDIFF & Active C. difficile toxoid vaccine. Phase II placebo-controlled for primary CDI prevention (NCT00772343)..$^{93-95}$ \\
\hline VP 2062I & Nontoxigenic C. difficile. Phase II trial for prevention of CDI recurrence (NCT0I259726). ${ }^{96}$ \\
\hline
\end{tabular}




\section{Intravenous immunoglobulin (IVlg)/monoclonal antibodies}

Although pooled IVIg has been used in cases of severe acute and recurrent CDI, there are no randomized controlled clinical trials evaluating efficacy. ${ }^{76-80}$ IVIg may be considered as an adjunctive treatment option in those who are hypogammaglobulinemic, have failed initial therapies, or in seriously ill patients in whom surgery is being considered, until results from large, randomized controlled trials should become available. ${ }^{80}$

\section{Human monoclonal antibodies against C. difficile toxins $A(C D A I)$ and $B(C D B I)$}

A single infusion of human monoclonal antibodies against $C$. difficile toxins A (CDA1) and B (CDB1) dosed at $10 \mathrm{mg} / \mathrm{kg}$ body weight was evaluated in a Phase II randomized, double-blind, placebo-controlled study in the treatment of 200 symptomatic individuals with CDI who were being treated with standard therapy of either metronidazole or vancomycin. ${ }^{81}$ The primary outcome was recurrence of infection during the 84 days after the administration of the study drug. The rate of recurrent CDI in the group of patients treated with monoclonal antibodies was $7 \%$ versus $25 \%$ in the placebo group $(P<0.001)$. The recurrence rates among patients with the epidemic BI/NAP1/027 strain were $8 \%$ for the antibody group and $32 \%$ for the placebo group $(P=0.06)$. However, there were no significant differences in the severity of diarrhea, the median or mean number of days to the resolution of diarrhea, or in treatment failures between the two groups. Phase III trials validating monoclonal antibody therapy of CDI are currently underway. ${ }^{82,83}$

Recombinant single-domain antibody fragments targeting the cell receptor binding domain of toxin $\mathrm{A}$ and toxin $\mathrm{B}$ have shown favorable characteristics such as high production yield, potent toxin neutralization, and intrinsic stability. ${ }^{84}$ These recombinant single-domain antibody fragments are attractive systemic therapeutics, but more studies are needed to assess its true efficacy in the treatment of CDI.

\section{Fecal transplantation}

Fecal transplantation or bacteriotherapy, also referred to as fecal microbiota transplant and intestinal microbiota transplant, using intestinal microorganisms from a healthy donor, has been used to treat patients with relapsing CDI as an alternative to antibiotic therapy in an effort to restore normal colonic microbiota with positive results. ${ }^{85-88}$ Challenging issues including donor selection (related versus unrelated donor), screening donors for transmissible infectious diseases, standardization of stool preparation techniques, insurance reimbursement for the procedure and donor testing, and long term safety and efficacy concerns need to be evaluated systematically. A systematic literature review, including 27 studies and case reports, found 317 evaluable subjects and reported an overall success rate of $92 \%$, with $89 \%$ of patients responding after a single treatment. ${ }^{88}$ Randomized controlled clinical trials are needed to support this approach and to better determine the best route of transplantation.

The first attempt at an open-label, randomized, controlled trial evaluating fecal bacteriotherapy in patients with relapsed $\mathrm{CDI}$ after at least one course of vancomycin or metronidazole was recently published.$^{89}$ In this study, the subjects were randomly assigned to one of three therapeutic interventions: either vancomycin $500 \mathrm{mg}$ orally four times daily for 4 or 5 days followed by bowel lavage on the last day of antibiotic therapy with subsequent infusion of donor feces through a nasoduodenal tube the next day; vancomycin $500 \mathrm{mg}$ orally four times daily for 14 days; or vancomycin $500 \mathrm{mg}$ orally for 4 or 5 days followed by bowel lavage on the last day of antibiotic therapy. The primary endpoint of the study was resolution of CDI-associated diarrhea (cure) without relapse at 10 weeks after initiation of the therapeutic regimen. Response rate to the fecal bacteriotherapy group was $81 \%$ after the first infusion, while in the vancomycin only group, the response rate was $31 \%(P<0.001)$ and in the vancomycin followed by bowel lavage group, the response rate was $23 \%(P<0.001)$. This finding supports prior uncontrolled reports and encourages further investigation into optimal use of antibiotics and fecal bacteriotherapy in the management of CDI and of the role of the fecal microbiome in the management and prevention of other gastrointestinal and metabolic conditions.

\section{Probiotics}

Probiotics are preparations of live microorganisms, including the Bifidobacterium, Saccharomyces, and Lactobacillus species, and have been used as an attempt to prevent or treat CDI. ${ }^{90-93}$ The postulated mechanisms of action advocating use of these products include the fact that probiotics enhance mucosal barrier function because they have been reported to enhance mucin secretion, provide colonization resistance, produce bacteriocins, increase production of secretory immunoglobulin A, produce a balanced T-helper cell response, as well as increase production of interleukin 10, and transform growth factor beta, both of which play a role in the development of immunologic tolerance to antigens..$^{91}$ In vitro studies have shown that Saccharomyces boulardii acts as an antitoxin 
blocking toxin receptor site and causes direct destruction of C. difficile toxins A and B. ${ }^{91,92}$

Recently published studies and reviews favor the use of probiotics for the prevention of CDI and antibiotic-associated diarrhea. ${ }^{92,93}$ However, many potential flaws in study designs were identified in these trials and additional, appropriately powered studies are needed to confirm these findings. Current treatment guidelines do not advocate the routine use of probiotics for the treatment of CDI given the lack of definitive evidence of effectiveness and the potential risk of bloodstream infection. ${ }^{1}$

\section{ACAM-CDIFF}

A $C$. difficile toxoid vaccine as an immunologic approach for the prevention and treatment of CDI is currently under investigation. ${ }^{94-96} \mathrm{An}$ intramuscular antitoxin $\mathrm{A}$ and $\mathrm{B}$ vaccine was found to be well tolerated in 200 subjects in six Phase I studies with successful subsequent production of IgG against toxin $\mathrm{A}$ and $\mathrm{B}$ in most subjects. ${ }^{94,95}$ Lower response rates in those aged over 70 years compared with those aged 25 years were observed. A Phase II study was completed in June 2012 comparing $C$. difficile toxoid vaccine versus toxoid vaccine with adjuvant versus placebo. The final results of this study have not been published. ${ }^{96}$

\section{Clostridium difficile-conjugated vaccines}

C. difficile can express three polysaccharides (PS-1, PS-2, and PS-3) on the surface of the microorganism. ${ }^{97-99}$ Current ongoing investigations using PS-2, a complex made up of hexaglocosyl repeating blocks as targets for conjugated C. difficile vaccines, are in development. A glucoconjugate vaccine composed of PS-2 and the diphtheria toxoid variant CRM has been shown to be highly immunogenic in mice. ${ }^{97}$ Two independent studies have described the chemical synthesis of the phosphorylated and nonphosphorylated hexaglycosyl repeating blocks of PS-2.98,99 These molecules, when conjugated to a protein carrier, are immunogenic in mice. Notably, these investigators have described that the stools of hospitalized patients infected with $C$. difficile were found to contain specific IgA antibodies that recognize the synthetic nonphosphorylated hexasaccharide, suggesting that PS-2 is antigenic in humans. ${ }^{99}$ Both the natural polysaccharide and the synthetic substructure are currently under study as potential conjugate vaccine candidates against CDI.

\section{VP 2062I}

VP20621 is comprised of non-toxigenic $C$. difficile spores that have been shown to be protective against CDI challenge in the hamster model. ${ }^{100}$ In humans, multiple doses of VP20621 were well tolerated in 27 volunteers at all dose levels, and oral administration resulted in positive non-toxigenic $C$. difficile stool cultures by day 6 , suggesting rapid colonization of the GI tract. Currently, a Phase II trial, evaluating the safety and efficacy of VP20621 administered after the completion of standard CDI therapy for the prevention of recurrence of CDI in adults is ongoing. ${ }^{39,101}$

\section{Conclusion}

Fidaxomicin represents an important development in the treatment of CDI with significant advantages over the other currently available antimicrobial agents. Fidaxomicin should be considered as first-line therapy for the management of CDI with high risk for relapse and recurrent CDI especially in those populations, including those receiving concomitant antibiotics, those with first relapse of CDI, those with renal dysfunction, older individuals, and in those with cancer. ${ }^{12,37-41}$

\section{Disclosure}

Fredy Chaparro-Rojas has no conflicts of interest to report. Kathleen M Mullane is on advisory boards for Optimer Pharmaceuticals and Merck and is involved in clinical trials for Actelion Pharmaceuticals, Astellas Pharma, Chimerix, Merck, Optimer Pharmaceuticals, and ViroPharma. The authors report no other conflicts of interest in this work.

\section{References}

1. Cohen SH, Gerding DN, Johnson S, et al; for Society for Healthcare Epidemiology of America, Infectious Diseases Society of America. Clinical practice guidelines for Clostridium difficile infection in adults: 2010 update by the society for healthcare epidemiology of America (SHEA) and the infectious diseases society of America (IDSA). Infect Control Hosp Epidemiol. 2010;31(5):431-455.

2. Bartlett JG, Taylor NS, Chang T, Dzink J. Clinical and laboratory observations in Clostridium difficile colitis. Am J Clin Nutr. 1980; 33(Suppl 11):2521-2526.

3. George WL, Rolfe RD, Finegold SM. Clostridium difficile and its cytotoxin in feces of patients with antimicrobial agent-associated diarrhea and miscellaneous conditions. J Clin Microbiol. 1982;15(6):1049-1053.

4. Kelly CP, Pothoulakis C, LaMont JT. Clostridium difficile colitis. N Engl J Med. 1994;330(4):257-262.

5. Lucado J, Gould C, Elixhauser A. Clostridium Difficile Infections (CDI) in Hospital Stays, 2009. Healthcare Cost and Utilization Project Statistical Brief\#124. Rockville, MD: Agency for Healthcare Research and Quality; 2012. Available from: http://www.hcup-us.ahrq.gov/reports/statbriefs/ sb124.pdf. Accessed April 29, 2013.

6. Rafii F, Sutherland JB, Cerniglia CE. Effects of treatment with antimicrobial agents on the human colonic microflora. Ther Clin Risk Manag. 2008;4(6):1343-1358.

7. Sun $X$, Savidge T, Feng H. The enterotoxicity of Clostridium difficile. Toxins (Basel). 2010;2(7):1848-1880.

8. Starr JM, Impallomeni M. Risk of diarrhoea, Clostridium difficile and cefotaxime in the elderly. Biomed Pharmacother. 1997;51(2): $63-67$. 
9. Barc MC, Depitre C, Corthier G, Collignon A, Su WJ, Bourlioux P. Effects of antibiotics and other drugs on toxin production in Clostridium difficile in vitro and in vivo. Antimicrob Agents Chemother. 1992;36(6):1332-1335.

10. Lessa FC, Gould CV, McDonald LC. Current status of Clostridium difficile infection epidemiology. Clin Infect Dis. 2012;55 Suppl 2: S65-S70.

11. Bartlett JG. The case for vancomycin as the preferred drug for treatment of Clostridium difficile infection. Clin Infect Dis. 2008;46(10): 1489-1492.

12. Mullane KM, Miller MA, Weiss K, et al. Efficacy of fidaxomicin versus vancomycin as therapy for Clostridium difficile infection in individuals taking concomitant antibiotics for other concurrent infections. Clin Infect Dis. 2011;53(5):440-447.

13. Bauer MP, Kuijper EJ, van Dissel JT; for European Society of Clinical Microbiology and Infectious Diseases. European Society of Clinical Microbiology and Infectious Diseases (ESCMID): treatment guidance document for Clostridium difficile infection (CDI). Clin Microbio Infect. 2009;15(12):1067-1079.

14. Recommendations for preventing the spread of vancomycin resistance recommendations of the Hospital Infection Control Practices Advisory Committee (HICPAC). Am J Infect Control. 1995;23(2):87-94.

15. Al-Nassir WN, Sethi AK, Li Y, Pultz MJ, Riggs MM, Donskey CJ. Both oral metronidazole and oral vancomycin promote persistent overgrowth of vancomycin-resistant enterococci during treatment of Clostridium difficile-associated disease. Antimicrob Agents Chemother. 2008;52(7):2403-2406.

16. Zar FA, Bakkanagari SR, Moorthi KM, Davis MB. A comparison of vancomycin and metronidazole for the treatment of Clostridium difficile-associated diarrhea, stratified by disease severity. Clin Infect Dis. 2007;45(3):302-307.

17. Louie TJGM, Grimard D, Johnson S, Poirier A, Weiss K; for the Tolevamer Study Group. Results of a phase III trial comparing tolevamer, vancomycin and metronidazole in patients with Clostridium difficile-associated diarrhea [abstact K-425a]. 2007.

18. Aslam S, Hamill RJ, Musher DM. Treatment of Clostridium difficileassociated disease: old therapies and new strategies. Lancet Infect Dis. 2005;5(9):549-557.

19. Baines SD, O'Connor R, Freeman J, et al. Emergence of reduced susceptibility to metronidazole in Clostridium difficile. $J$ Antimicrob Chemother. 2008;62(5):1046-1052.

20. Rupnik M, Wilcox MH, Gerding DN. Clostridium difficile infection: new developments in epidemiology and pathogenesis. Nat Rev Microbiol. 2009;7(7):526-536.

21. Bolton RP, Culshaw MA. Faecal metronidazole concentrations during oral and intravenous therapy for antibiotic associated colitis due to Clostridium difficile. Gut. 1986;27(10):1169-1172.

22. Louie TJ, Miller MA, Mullane KM, et al; for OPT-80-003 Clinical Study Group. Fidaxomicin versus vancomycin for Clostridium difficile infection. N Engl J Med. 2011;364(5):422-431.

23. Cornely OA, Crook DW, Esposito R, et al; for OPT-80-004 Clinical Study Group. Fidaxomicin versus vancomycin for infection with Clostridium difficile in Europe, Canada, and the USA: a double-blind, non-inferiority, randomised controlled trial. Lancet Infect Dis. 2012; 12(4):281-289.

24. Patino HSC, Louie T, Bernardo P, Friedland I; for the CDI Study Group. Efficacy and safety of the lipopeptide CB-183,315 for the treatment of Clostridium difficile infection [Abstract K-205a]. Proceedings of the 51st Internatl Congr Antimicr Ag Chemother; September 17-20, 2011; Chicago, IL.

25. Johnson S. Recurrent Clostridium difficile infection: a review of risk factors, treatments, and outcomes. $J$ Infect. 2009;58(6):403-410.

26. McFarland LV, Elmer GW, Surawicz CM. Breaking the cycle: treatment strategies for 163 cases of recurrent Clostridium difficile disease. Am J Gastroenterol. 2002;97(7):1769-1775.

27. Mullane KM, Gorbach S. Fidaxomicin: first-in-class macrocyclic antibiotic. Expert Rev Anti Infect Ther. 2011;9(7):767-777.
28. Parenti F, Pagani H, Beretta G. Lipiarmycin, a new antibiotic from Actinoplanes. I. Description of the producer strain and fermentation studies. J Antibiot (Tokyo). 1975;28(4):247-252.

29. Theriault RJ, Karwowski JP, Jackson M, et al. Tiacumicins, a novel complex of 18-membered macrolide antibiotics. I. Taxonomy, fermentation and antibacterial activity. $J$ Antibiot (Tokyo). 1987;40(5): 567-574.

30. Goldstein EJ, Citron DM, Sears P, Babakhani F, Sambol SP, Gerding DN. Comparative susceptibilities to fidaxomicin (OPT-80) of isolates collected at baseline, recurrence, and failure from patients in two phase III trials of fidaxomicin against Clostridium difficile infection. Antimicrob Agents Chemother. 2011;55(11):5194-5199.

31. Biedenbach DJ, Ross JE, Putnam SD, Jones RN. In vitro activity of fidaxomicin (OPT-80) tested against contemporary clinical isolates of Staphylococcus spp. and Enterococcus spp. Antimicrob Agents Chemother. 2010;54(5):2273-2275.

32. Coronelli C, White RJ, Lancini GC, Parenti F. Lipiarmycin, a new antibiotic from Actinoplanes. II. Isolation, chemical, biological and biochemical characterization. J Antibiot (Tokyo). 1975;28(4): $253-259$.

33. Seddon JSP. Preliminary OPT- 80 Mode of Action Studies. Optimer Pharmaceuticals, Inc. Report Number BIO090203A. 2003.

34. Sergio S, Pirali G, White R, Parenti F. Lipiarmycin, a new antibiotic from Actinoplanes III. Mechanism of action. J Antibiot (Tokyo). 1975;28(7):543-549.

35. Srivastava A, Talaue M, Liu S, et al. New target for inhibition of bacterial RNA polymerase: 'switch region'. Curr Opin Microbiol. 2011;14(5):532-543.

36. Sears PBF, Citron DM. Typing and Susceptibility of Bacterial Isolates from the OPT-80 (PAR-101) Phase 2A Study for C. difficile-associated Diarrhea. [Poster] 9th Biennial Congress of the Anaerobe Society of the Americas, Long Beach, CA; 2008.

37. Crook DW, Walker AS, Kean Y, et al; for Study 003/004 Teams. Fidaxomicin versus vancomycin for Clostridium difficile infection: meta-analysis of pivotal randomized controlled trials. Clin Infect Dis. 2012;55 Suppl 2:S93-S103.

38. Mullane KGY, Crook D, Cornely OA, Miller M, Louie T, Gorbach S. Renal Impairment and Response to Fidaxomicin versus Vancomycin in Patients with Clostridium difficile Infection [abstract]. Proceedings of the 49th Annual Infectious Diseases Society of America Meeting; October 20-23, 2011; Boston MA.

39. Cornely OAMM, Fantin B, Mullane K, Kean Y, Gorbach S. Clostridium difficile-associated diarrhea in cancer patients treated with fidaxomicin or vancomycin. Proceedings of the American Society of Clinical Oncology Abstract \#9067; June 1-5, 2012; Chicago, IL.

40. Cornely OAMM, Fantin B, Mullane K, Kean Y, Gorbach S. Clinical outcomes for cancer patients with Clostridium difficile infection (CDI) Poster 2289. Proceedings of the European Congress of Clinical Microbiology and Infectious Diseases. March 31-April 3, 2012; London, UK.

41. Louie TJ, Miller MA, Crook DW, et al. Effect of age on treatment outcomes in Clostridium difficile infection. $J$ Am Geriatr Soc. 2013;61(2):222-230.

42. Johnson AP. Drug evaluation: OPT-80, a narrow-spectrum macrocyclic antibiotic. Curr Opin Investig Drugs. 2007;8(2):168-173.

43. Babakhani F, Gomez A, Robert N, Sears P. Postantibiotic effect of fidaxomicin and its major metabolite, OP-1118, against Clostridium difficile. Antimicrob Agents Chemother. 2011;55(9):4427-4429.

44. Sears P, Louie T, Mullane KM, et al. Pharmacokinetics/pharmacodynamics $(\mathrm{PK} / \mathrm{PD})$ of fidaxomicin in treatment of Clostridium difficile infection (CDI). Proceedings of the 49th Interscience Conference on Antimicrobial Agents and Chemotherapy (ICAAC). September 12-15, 2009; San Francisco, CA.

45. Louie T, Miller M, Donskey C, Mullane K, Goldstein EJ. Clinical outcomes, safety, and pharmacokinetics of OPT- 80 in a phase 2 trial with patients with Clostridium difficile infection. Antimicrob Agents Chemother. 2009;53(1):223-228. 
46. Okumu FWR, Sears P, Shue YK. Safety and Pharmacokinetics of OPT-80, a novel antibiotic for treatment of Clostridium difficile associated diarrhea (CDAD). Proceedings of the 44th Interscience Conference on Antimicrobial Agents and Chemotherapy (ICAAC). October 30-November 2, 2004; Washington, DC.

47. Sears P, Crook DW, Louie TJ, Miller MA, Weiss K. Fidaxomicin attains high fecal concentrations with minimal plasma concentrations following oral administration in patients with Clostridium difficile infection. Clin Infect Dis. 2012;55 Suppl 2:S116-S120.

48. DIFICID ${ }^{\circledR}$ [prescribing information]. San Diego, CA: Optimer Pharmaceuticals, Inc; May 2011, Data on File. Clinical Study Report OPT80-004 Final. June 4, 2010. Optimer Pharmaceuticals, Inc, Data on File. Clinical Study Report OPT-80-003 Final. June 17, 2010 (Version 2). Optimer Pharmaceuticals, Inc. Available from: http://www.drugs.com/ comments/fidaxomicin/dificid.html. Accessed April 29, 2013.

49. Tannock GW, Munro K, Taylor C, et al. A new macrocyclic antibiotic, fidaxomicin (OPT-80), causes less alteration to the bowel microbiota of Clostridium difficile-infected patients than does vancomycin. Microbiology. 2010;156(Pt 11):3354-3359.

50. Nerandzic MM, Mullane K, Miller MA, Babakhani F, Donskey CJ. Reduced acquisition and overgrowth of vancomycin-resistant enterococci and Candida species in patients treated with fidaxomicin versus vancomycin for Clostridium difficile infection. Clin Infect Dis. 2012; 55 Suppl 2:S121-S126.

51. Louie TJ, Cannon K, Byrne B, et al. Fidaxomicin preserves the intestinal microbiome during and after treatment of Clostridium difficile infection (CDI) and reduces both toxin reexpression and recurrence of CDI. Clin Infect Dis. 2012;55 Suppl 2:S132-S142.

52. Babakhani F, Bouillaut L, Sears P, Sims C, Gomez A, Sonenshein AL. Fidaxomicin inhibits toxin production in Clostridium difficile. J Antimicrob Chemother. 2013;68(3):515-522.

53. Babakhani F, Bouillaut L, Gomez A, Sears P, Nguyen L, Sonenshein AL. Fidaxomicin inhibits spore production in Clostridium difficile. Clin Infect Dis. 2012;55 Supp1 2:S162-S169.

54. DIFICID ${ }^{\mathrm{TM}}$ oral tablets, fidaxomicin oral tablets [prescribing information]. San Diego, CA: Optimer Pharmaceuticals, Inc; 2011.

55. Miller MAMK, Weiss K, Lentnek A, et al. Faster time to resolution of diarrhea with fidaxomicin vs vancomycin in patients with Clostridium difficile infection (CDI) [abstract]. Proceedings of the 47th Annual Infectious Diseases Society of America Meeting. October 29-November 1, 2009; Philadelphia, PA.

56. Drugs.com. User reviews for Dificid [webpage on the Internet]. Drugs.com; 2012. Available from: http://www.drugs.com/comments/ fidaxomicin/dificid.html. Accessed December 28, 2012.

57. Musher DM, Logan N, Hamill RJ, et al. Nitazoxanide for the treatment of Clostridium difficile colitis. Clin Infect Dis. 2006;43(4):421-427.

58. Musher DM, Logan N, Bressler AM, Johnson DP, Rossignol JF. Nitazoxanide versus vancomycin in Clostridium difficile infection: a randomized, double-blind study. Clin Infect Dis. 2009;48(4):e41-e46.

59. Garey KW, Jiang ZD, Bellard A, Dupont HL. Rifaximin in treatment of recurrent Clostridium difficile-associated diarrhea: an uncontrolled pilot study. J Clin Gastroenterol. 2009;43(1):91-93.

60. Rubin DT, Sohi S, Glathar M, Thomas T, Yadron N, Surma BL. Rifaximin is effective for the treatment of Clostridium difficileassociated diarrhea: results of an open-label pilot study. Gastroenterol Res Pract. 2011;2011:106978.

61. Johnson S, Schriever C, Galang M, Kelly CP, Gerding DN. Interruption of recurrent Clostridium difficile-associated diarrhea episodes by serial therapy with vancomycin and rifaximin. Clin Infect Dis. 2007;44(6): 846-848.

62. Johnson S, Schriever C, Patel U, Patel T, Hecht DW, Gerding DN. Rifaximin Redux: treatment of recurrent Clostridium difficile infections with rifaximin immediately post-vancomycin treatment. Anaerobe. 2009;15(6):290-291.

63. Nelson RL, Kelsey P, Leeman H, et al. Antibiotic treatment for Clostridium difficile-associated diarrhea in adults. Cochrane Database Syst Rev. 2011;9:CD004610.
64. Citron DM, Merriam CV, Tyrrell KL, Warren YA, Fernandez H, Goldstein EJ. In vitro activities of ramoplanin, teicoplanin, vancomycin, linezolid, bacitracin, and four other antimicrobials against intestinal anaerobic bacteria. Antimicrob Agents Chemother. 2003;47(7): 2334-2338.

65. Dudley MN, McLaughlin JC, Carrington G, Frick J, Nightingale CH, Quintiliani R. Oral bacitracin vs vancomycin therapy for Clostridium difficile-induced diarrhea. A randomized double-blind trial. Arch Intern Med. 1986;146(6):1101-1104.

66. Larson KC, Belliveau PP, Spooner LM. Tigecycline for the treatment of severe Clostridium difficile infection. Ann Pharmacother. 2011; 45(7-8): 1005-1010.

67. Wullt M, Odenholt I. A double-blind randomized controlled trial of fusidic acid and metronidazole for treatment of an initial episode of Clostridium difficile-associated diarrhoea. J Antimicrob Chemother. 2004;54(1):211-216.

68. Noren T, Wullt M, Akerlund T, Bäck E, Odenholt I, Burman LG. Frequent emergence of resistance in Clostridium difficile during treatment of C. difficile-associated diarrhea with fusidic acid. Antimicrob Agents Chemother. 2006;50(9):3028-3032.

69. Farver DK, Hedge DD, Lee SC. Ramoplanin: a lipoglycodepsipeptide antibiotic. Ann Pharmacother. 2005;39(5):863-868.

70. Freeman J, Baines SD, Jabes D, Wilcox MH. Comparison of the efficacy of ramoplanin and vancomycin in both in vitro and in vivo models of clindamycin-induced Clostridium difficile infection. J Antimicrob Chemother. 2005;56(4):717-725.

71. Pullman J, Prieto J, Leach TS. Ramoplanin vs vancomycin in the treatment of C. difficile diarrhea: a phase 2 study [abstract K-985a]. Proceedings of the 44th Annual Interscience Conference on Antimicrobial Agents and Chemotherapy. October 30-November 2, 2004; Washington, DC.

72. Cornely OA. Current and emerging management options for Clostridium difficile infection: what is the role of fidaxomicin? Clin Microbiol Infect. 2012;18 Suppl 6:28-35.

73. Venugopal AA, Johnson S. Current state of Clostridium difficile treatment options. Clin Infect Dis. 2012;55 Suppl 2:S71-S76.

74. Snydman DR, Jacobus NV, McDermott LA. Activity of a novel cyclic lipopeptide, CB-183,315, against resistant Clostridium difficile and other Gram-positive aerobic and anaerobic intestinal pathogens. Antimicrob Agents Chemother. 2012;56(6):3448-3452.

75. Mascio CT, Mortin LI, Howland KT, et al. In vitro and in vivo characterization of CB-183,315, a novel lipopeptide antibiotic for treatment of Clostridium difficile. Antimicrob Agents Chemother. 2012;56(10): 5023-5030.

76. Saito T, Kimura S, Tateda K, et al. Evidence of intravenous immunoglobulin as a critical supportive therapy against Clostridium difficile toxin-mediated lethality in mice. JAntimicrob Chemother. 2011;66(5): 1096-1099.

77. Wilcox MH. Descriptive study of intravenous immunoglobulin for the treatment of recurrent Clostridium difficile diarrhoea. $J$ Antimicrob Chemother. 2004;53(5):882-884.

78. Juang P, Skledar SJ, Zgheib NK, et al. Clinical outcomes of intravenous immune globulin in severe clostridium difficile-associated diarrhea. $\mathrm{Am}$ J Infect Control. 2007;35(2):131-137.

79. Leung DY, Kelly CP, Boguniewicz M, Pothoulakis C, LaMont JT, Flores A. Treatment with intravenously administered gamma globulin of chronic relapsing colitis induced by Clostridium difficile toxin. J Pediatr. 1991;118(4 Pt 1):633-637.

80. Abougergi MS, Kwon JH. Intravenous immunoglobulin for the treatment of Clostridium difficile infection: a review. Dig Dise Sci. 2011; 56(1):19-26.

81. Lowy I, Molrine DC, Leav BA, et al. Treatment with monoclonal antibodies against Clostridium difficile toxins. New Engl J Med. 2010;362(3):197-205.

82. ClinicalTrials.gov. A study of MK-3415, MK-6072, and MK-3415A in participants receiving antibiotic therapy for Clostridium difficile infection (MK-3415A-001 AM2) (MODIFY I). ClinicalTrials.gov; 2013. Available from: http://www.clinicaltrials.gov/ct2/show/NCT01241552. Accessed April 29, 2013. 
83. ClinicalTrials.gov. A study of MK-6072 and MK-3415A in participants receiving antibiotic therapy for Clostridium difficile infection (MK-3415A-002) (MODIFY II). ClinicalTrials.gov; 2013. Available from: http://www.clinicaltrials.gov/ct2/show/NCT01513239. Accessed April 29, 2013.

84. Hussack G, Arbabi-Ghahroudi M, van Faassen H, et al. Neutralization of Clostridium difficile toxin A with single-domain antibodies targeting the cell receptor binding domain. J Biol Chem. 2011;286(11): 8961-8976.

85. Borody TJ, Warren EF, Leis SM, Surace R, Ashman O, Siarakas S. Bacteriotherapy using fecal flora: toying with human motions. J Clin Gastroenterol. 2004;38(6):475-483.

86. Khanna S, Pardi DS. Clostridium difficile infection: new insights into management. Mayo Clin Proc. 2012;87(11):1106-1117.

87. Bakken JS, Borody T, Brandt LJ, et al; for Fecal Microbiota Transplantation Workgroup. Treating Clostridium difficile infection with fecal microbiota transplantation. Clin Gastroenterol Hepatol. 2011;9(12): 1044-1049.

88. Gough E, Shaikh H, Manges AR. Systematic review of intestinal microbiota transplantation (fecal bacteriotherapy) for recurrent Clostridium difficile infection. Clin Infect Dis. 2011;53(10):994-1002.

89. van Nood E, Vrieze A, Nieuwdorp M, et al. Duodenal infusion of donor feces for recurrent Clostridium difficile. N Engl J Med. 2013;368(5): $407-415$

90. Videlock EJ, Cremonini F. Meta-analysis: probiotics in antibioticassociated diarrhoea. Aliment Pharmacol Ther. 2012;35(12): 1355-1369.

91. Friedman G. The role of probiotics in the prevention and treatment of antibiotic-associated diarrhea and Clostridium difficile colitis. Gastroenterol Clin North Am. 2012;41(4):763-779.

92. Johnston BC, Ma SS, Goldenberg JZ, et al. Probiotics for the prevention of Clostridium difficile-associated diarrhea: a systematic review and meta-analysis. Ann Intern Med. 2012;157(12):878-888.

93. Hempel S, Newberry SJ, Maher AR, et al. Probiotics for the prevention and treatment of antibiotic-associated diarrhea: a systematic review and meta-analysis. JAMA. 2012;307(18):1959-1969.
94. Foglia G, Shah S, Luxemburger C, Pietrobon PJ. Clostridium difficile: development of a novel candidate vaccine. Vaccine. 2012;30(29): 4307-4309.

95. Folgia G. ACAM-CDIFF: An active vaccine against Clostridium difficile infection. Proceedings of the 10th Anaerobe Society of the Americas. July 7-10, 2010.

96. ClinicalTrials.gov. Study of a Clostridium difficile toxoid vaccine (ACAM-CDIFF ${ }^{\mathrm{TM}}$ ) in subjects with Clostridium difficile infection [webpage on the Internet]. ClinicalTrials.gov; 2012. Available from: http:/www.clinicaltrials.gov/ct2/show/NCT00772343. Accessed April 29, 2013

97. Cappelletti E, Romano MR, Cakici OS, et al. Conjugate vaccine against Clostridium difficile. Glycoconjugate Journal. 2011;28:265.

98. Danieli E, Lay L, Proietti D, Berti F, Costantino P, Adamo R. First synthesis of C. difficile PS-II cell wall polysaccharide repeating unit. Org Lett. 2011;13(3):378-381.

99. Oberli MA, Hecht ML, Bindschädler P, Adibekian A, Adam T, Seeberger PH. A possible oligosaccharide-conjugate vaccine candidate for Clostridium difficile is antigenic and immunogenic. Chem Biol. 2011;18(5):580-588.

100. Merrigan MM, Sambol SP, Johnson S, Gerding DN. New approach to the management of Clostridium difficile infection: colonisation with non-toxigenic $\mathrm{C}$. difficile during daily ampicillin or ceftriaxone administration. Int J Antimicrob Agents. 2009;33 Supp1 1:S46-S50.

101. ClinicalTrials.gov. Safety and efficacy of VP20621 for prevention of recurrent Clostridium difficile infection [webpage on the Internet]. ClinicalTrials.gov; 2012. Available from: http://www.clinicaltrials. gov/ct2/show/NCT01259726. Accessed April 29, 2013.

102. Cornely OA, Miller MA, Louie TJ, et al. Treatment of first recurrence of Clostridium difficile infection: fidaxomicin versus vancomycin. Clinical infectious diseases : an official publication of the Infectious Diseases Society of America. Aug 2012;55 Suppl 2:S154-161.
Infection and Drug Resistance

\section{Publish your work in this journal}

Infection and Drug Resistance is an international, peer-reviewed openaccess journal that focuses on the optimal treatment of infection (bacterial, fungal and viral) and the development and institution of preventive strategies to minimize the development and spread of resistance. The journal is specifically concerned with the epidemiology of antibiotic

\section{Dovepress}

resistance and the mechanisms of resistance development and diffusion in both hospitals and the community. The manuscript management system is completely online and includes a very quick and fair peerreview system, which is all easy to use. Visit http://www.dovepress.com/ testimonials.php to read real quotes from published authors. 